\title{
Selection of Power Semiconductor Switches - a Tool to Reduce Switching \& Conduction Losses of High Frequency Hybrid Resonant Inverter fed Induction Cooker
}

\author{
Nitai Pal, Senior Member, IACSIT, Pradip Kumar Sadhu*, Senior Member, IACSIT, Dola Sinha and \\ Atanu Bandyopadhyay
}

\begin{abstract}
An exhaustive method for the selection of different power semiconductor switches for high frequency hybrid resonant inverter fed induction heater is presented here. Heating coil of the induction heater is made of litz wire which minimizes the skin effect and proximity effect at high operating frequency. With the calculated optimum values of inductance and resistance of heating coil at a particular operating frequency, high frequency hybrid resonant inverter topology has been simulated using PSPICE software as well as constructing the experimental model of same rating. Obtained the voltage waveforms across heating coil and current waveforms through it, have been taken for further analysis. From this analysis, selection of suitable power semiconductor switches like IGBT, GTO and MOSFET are made. Waveforms have been shown to justify the feasibility for real implementation of high frequency hybrid resonant inverter fed induction heater in domestic applications.
\end{abstract}

Index Terms-Hybrid resonant inverter, Induction heater, PSPICE simulation, Semiconductor switches.

\section{INTRODUCTION}

In the process of induction heating, a disc of metal is surrounded by a copper coil through which an alternating current is made to flow. The disc has a finite diameter and thickness. It is placed at a given distance from the coil and concentric to it. Secondary current is induced in the disc and this induced current circulates around the outer surface of the disc resulting heating effect. Modern devices like IGBT's [1] make easier to apply induction-heating technique in kitchen heating-ranges for domestic use [2, 3]. Induction heating technique in heating-ranges is becoming a strong alternative to gas, normal electrical hotplates and microwave oven. Compared to dielectric heating as in microwave oven, the proposed technique of induction heating is more convenient

Manuscript submitted on December 23, 2010. This work was partially supported by the Unversity Grant Commission, India

N. Pal, P. K. Sadhu and D. Sinha are with Electrical Engineering Department, Indian School of Mines, Dhanbad, Jharkhand 826004, India (Emails: nitai_pal@rediffmail.com, pradip_sadhu@yahoo.co.in, and dola.sinha@gmail.com )

*P. K. Sadhu is corresponding author. Phone: +91326-2235478, fax: +91326-2296563.

A. Bandyopadhyay is with Electrical Engineering Department, Asansol Engineering College, Asansol, West Bengal, India. (E-mail: banerjee_atanu77123@rediffmail.com). and cost effective $[1,4]$. For example, in microwave oven, food is cooked in a special non-metallic bowel inside a closed chamber, while the proposed method would permit heating using normal house-hold metal utensils like steel pan, GI pressure-cooker, iron bowl etc., leading to a lot of savings in cost of utensils. The proposed topology also possesses a unique advantage for Indian sub-continental style of cooking $[3,7]$. Besides, the proposed induction heating system is absolutely safe from shock hazard during cooking $[4,5]$. The induction-heating system is also extremely rugged because of absence of red-hot temperature in the induction coil resulting in no deterioration or aging of coil [5]-[9].

For self-commutation, a resonant circuit is essential. It is assumed that the circuit is under damped; a mandatory condition for the circuit. The capacitor required for under damping can be connected in series or in parallel with the load. In the modern times, IGBTs, GTOs, MOSFETs are preferred to SCRs mainly because they offer convenient turn OFF characteristics. Some auxiliary circuits and equipment are required to minimize switching losses occurring at high frequencies. According to Koertzen et al. [10] the requirements for the induction heaters are as follows:

- Switching in high-frequency range

- High efficiency

- Power factor close to unity

- Wide power range and

- Reliability.

Induction heaters are usually designed to operate with a vessel made from a specific material, mainly cast iron or ferro-magnetic stainless steel. The following is therefore desired characteristic for the inverter;

- No reactive components other than the heating coil and the non-smooth filter inductor,

- No input or matching transformers,

- $50 \%$ duty ratio, simplifying the control and gate circuits,

- Zero current switching (ZCS) and / or zero voltage switching (ZVS),

- Clamped switch voltage and / or current,

- The use of uncontrolled voltage source.

Different inverter topologies suitable for induction heating and melting applications are presented in [11]. The 
comparison is based on the criteria such as input power factor, component ratings, maximum and minimum operating frequencies, operation under varying load conditions, inverter starting capability and system and control simplicity. Llorente et al. [12] have made a comparison between four inverter topologies commonly used in induction cookers. The considered topologies are the full-bridge inverter, the half-bridge inverter, and two single-switch inverters. All of them are designed for the same specifications and they are compared in aspects such as power device stresses, efficiency, frequency control, and electromagnetic emissions. In these papers, separate inverter configurations have been discussed \& compared, but no light is thrown to the type \& necessity of power semiconductor switches for different inverter topologies. Same circuit can respond differently with the variation in power switches. In this present paper, response of high frequency hybrid resonant inverter is tested \& verified with different power switches and finally appropriateness of the switches is confirmed. With the same designed parameters of the said inverter circuit, various switches such as IGBT, GTO and MOSFET have been used. Complete inverter configuration then has been simulated using PSPICE.

Hybrid resonant inverter is powered from single phase AC supply to energize the heating coil which is made of litz wire. This type of wire is configured by many strands of single insulated wire in order to reduce the losses caused by skin effect \& proximity effect.

\section{PRESENT SCHEME}

One hybrid resonant inverter consists of four semiconductor switches (IGBT's) for each heating-range. The switching frequency of present scheme lies between 25 to $35 \mathrm{kHz}$. The inverter is a combination of both series and parallel resonant circuits where the switching is made at zero current cross-over (ZCS). An H-bridge with its load impedance is shown in Figure 1. The load can be of series type, that is $Z_{S}$, or it can be a parallel type like $Z_{P}$. An advantage of the series circuit is that both zero current and zero voltage switching are possible.

The inverter for two cooking zones is shown in Figure 2 [1]. It consists of two parallel resonant circuits which represents two cooking zones. The two zones have diameters and output power levels of $14 \mathrm{~cm}$ for $1100 \mathrm{~W}$ and $18 \mathrm{~cm}$ for $1800 \mathrm{~W}$ respectively. Figure 3 represents the hybrid resonant inverter system for four cooking zones. The four zones have diameters and output power levels of $10 \mathrm{~cm}$ for $800 \mathrm{~W}, 14 \mathrm{~cm}$ for $1100 \mathrm{~W}, 18 \mathrm{~cm}$ for $1800 \mathrm{~W}$ and $22 \mathrm{~cm}$ for $2200 \mathrm{~W}$ respectively. Different diameters of induction coils have been chosen for different diameters of flat bed utensils. For getting maximum efficiency of the system, the coil diameter and the diameter of the utensils must be equal. Different control strategies have been discussed [13]-[19] to show that an optimum concerning efficiency occurs when switching around the zero crossing of the parallel resonance circuit. With the inverter implemented in an induction heating system, the total system efficiency (i.e. from the mains to the load) of around $88.2 \%$ has been achieved.
However, the full resonant current must pass through the switches resulting in $\mathrm{ON}$ losses. Another disadvantage is that the supply voltage must be reduced which means that a dc / dc converter must be used. Depending on the converter there will be reactive power consumption or more complexity. In a parallel load, $Z_{P}$ there would be lower ON losses in the switches but turn-on / turn-off losses would be more as the switching takes place at high voltage and current. Therefore, by using both series and parallel combined circuit, a hybrid inverter can be used to reduce the losses in the switches. Figure 4 shows a resonant inverter system for one cooking zone. The mode of operation basically consists of interaction between two resonant circuits where the energy is transferred from the series resonant circuit (consisting of $\mathrm{C}_{\mathrm{R}}$ and $\mathrm{L}_{1}$ ) to the parallel resonant circuit (consisting of $C_{R}, R_{L}$ and $L_{R}$ ). By turning on one of the transistor pairs $\mathrm{S} 1, \mathrm{~S} 4$ or $\mathrm{S} 2, \mathrm{~S} 3$ a resonant current starts flowing through $L_{1}$ to $C_{R}$ and when this circuit current is zero the transistors are switched off.

Thereafter the series resonant circuit is disconnected and the energy transferred to $C_{R}$ is now dissipated as heat in $R_{L}$ by the current flowing in the parallel resonant circuit. $\mathrm{R}_{\mathrm{L}}$ is mainly an equivalent resistance for the magnetic loss mechanism in the induction heating system and secondly it represents the ohmic resistance of the parallel resonant circuit components.

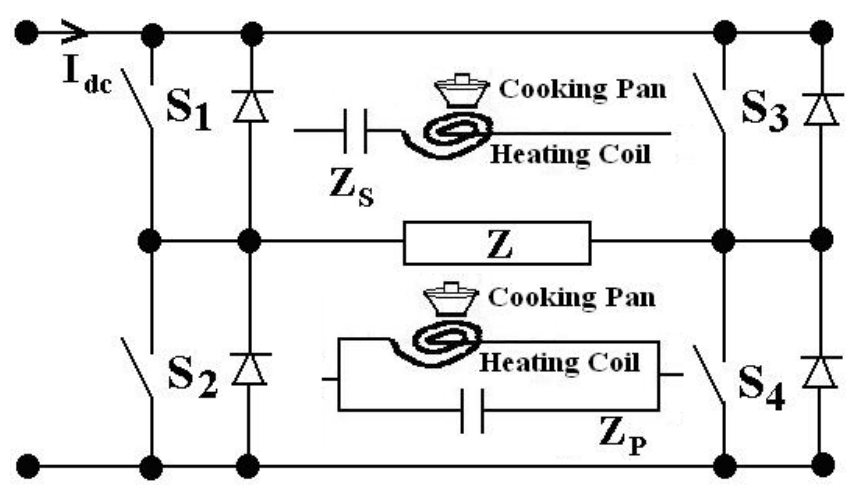

Figure 1: Inverter with resonant load

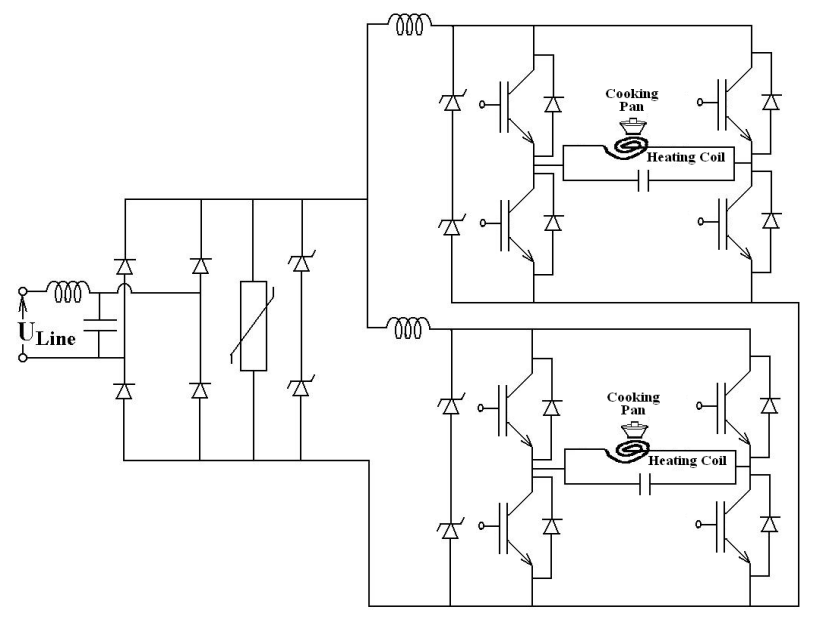

Figure 2: Hybrid resonant inverter system for two cooking zones [1] 


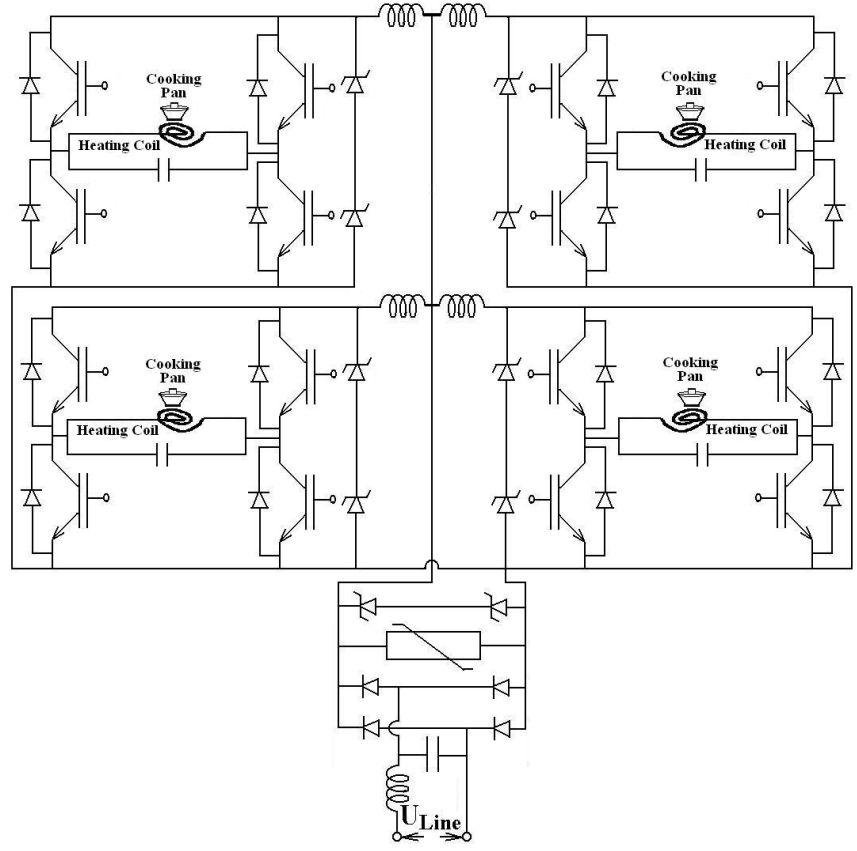

Figure 3: Hybrid resonant inverter system for four cooking zones

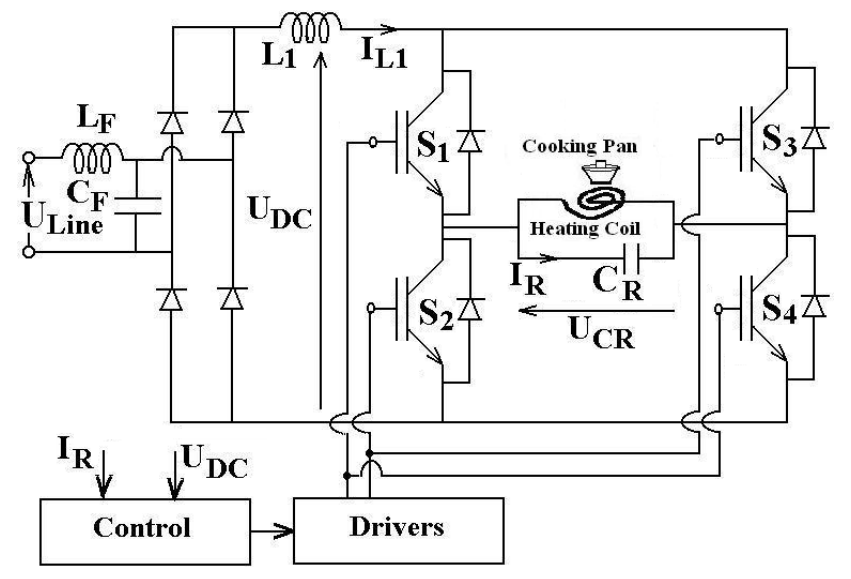

Figure 4: Hybrid resonant inverter system for one cooking zone

\section{TESTING CONDITIONS}

The circuit diagram used for the simulation work has been constructed using PSPICE software as shown in the Figure 5.

The parameters of the inverter configuration have been shown in Table 1.

TABLE1: INPUT PARAMETERS OF SIMULATION

\begin{tabular}{|l|l|}
\hline $\begin{array}{l}\text { Filter circuit } \\
\text { components }\end{array}$ & $\begin{array}{l}\mathrm{L} 1=50 \mathrm{uH}, \quad \mathrm{L} 2=100 \mu \mathrm{H}, \\
\mathrm{C} 1=5 \mu \mathrm{F}\end{array}$ \\
\hline $\begin{array}{l}\text { Heating coil parameters } \\
\text { (reflected values): }\end{array}$ & $\mathrm{L} 3=140 \mu \mathrm{H}, \mathrm{R} 1=0.002 \Omega$ \\
\hline Parallel capacitors $(\mathrm{C} 2):$ & $0.2 \mu \mathrm{F}$ \\
\hline Switching frequency & $30 \mathrm{kHz}$ \\
\hline
\end{tabular}

Firstly, the inverter circuit is simulated with IGBT as power switch. There after IGBT has been replaced by GTO \& MOSFET. In each case, coil current waveform \& voltage across it have been recorded \& investigated. A real time experiment has been carried out to validate the simulation result.

\section{RESUlT AND DisCUSSION}

With the selected circuit parameters \& configuration, following waveforms have been obtained using PSPICE software and real time experimental model for different power semiconductor switches:

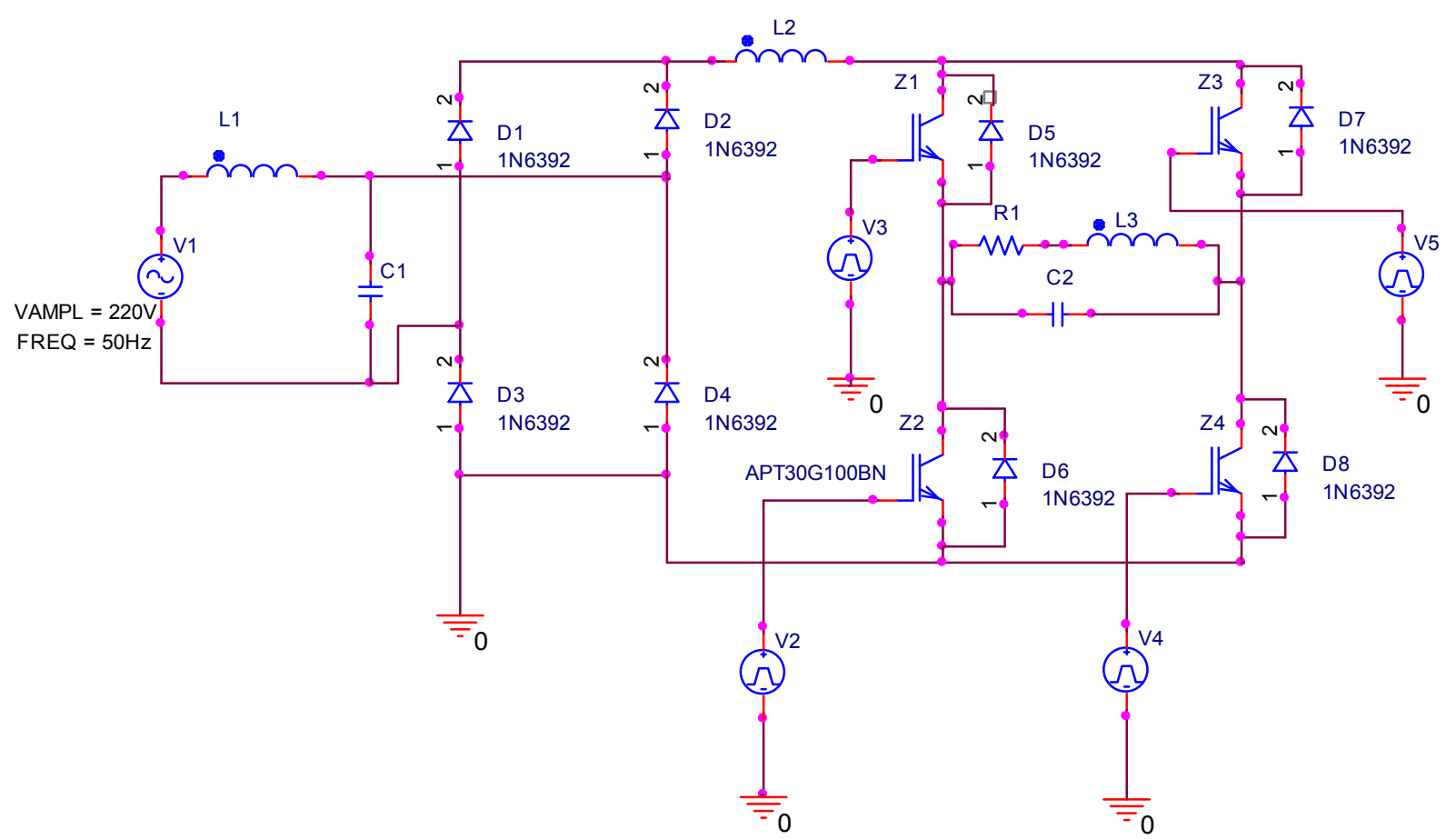

Figure 5: Circuit diagram for PSPICE Simulation of hybrid resonant inverter using IGBT 


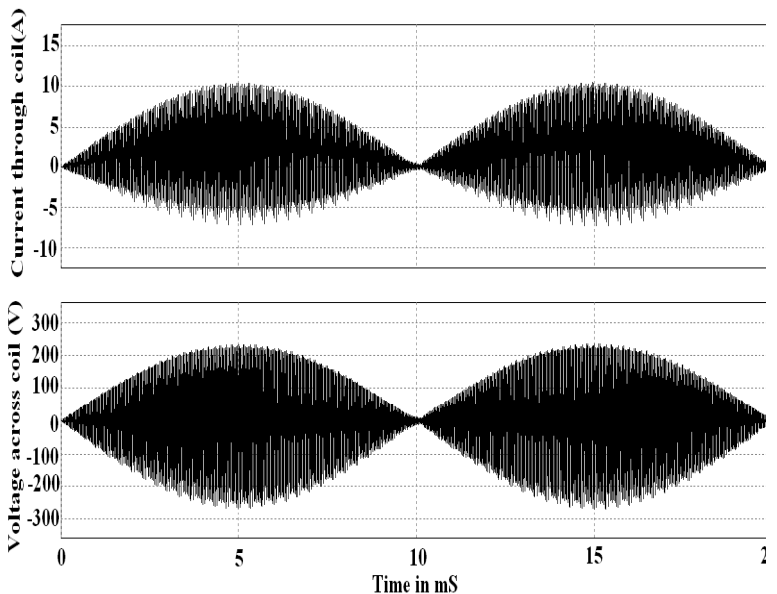

(a)

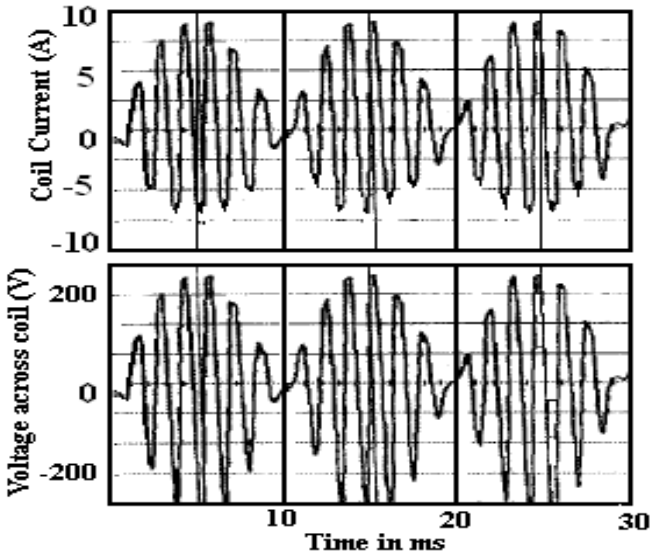

(b)

Figure 6: Coil current \& coil voltage using IGBT by (a) PSPICE software and (b) real time experimental model
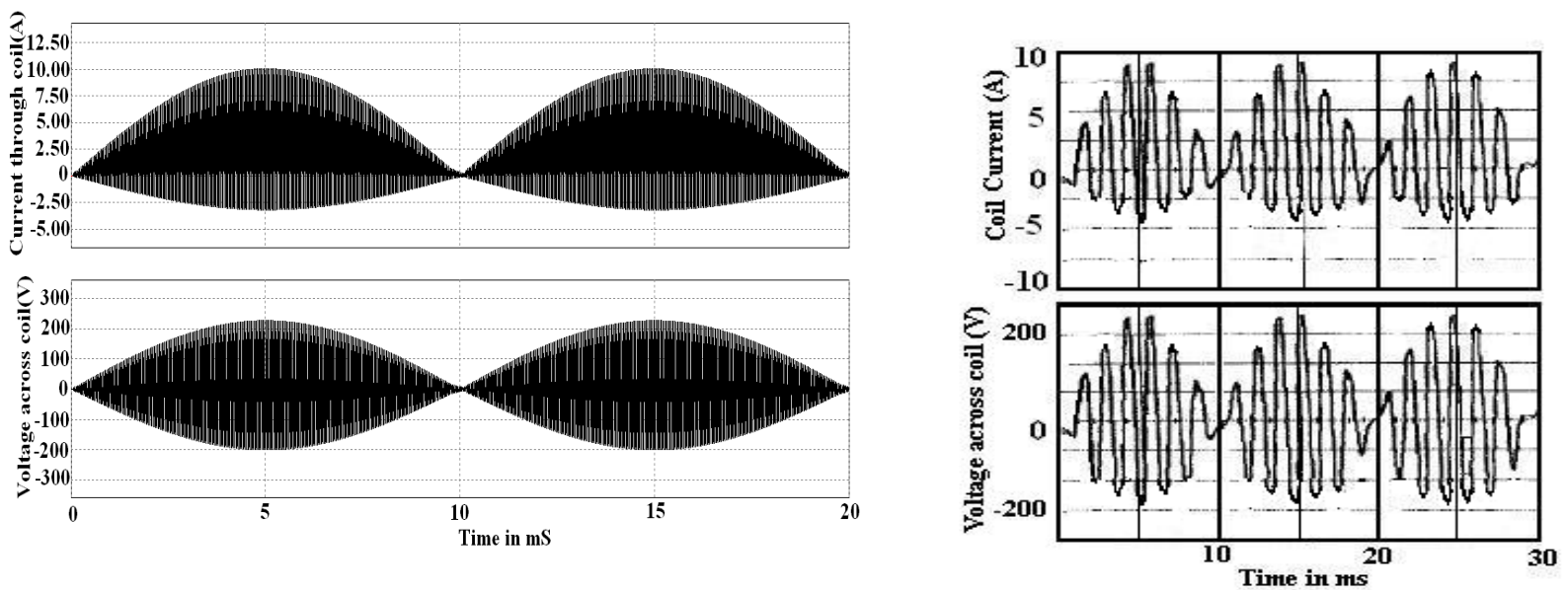

Figure 7: Coil current \& coil voltage using GTO by (a) PSPICE software and (b) real time experimental model

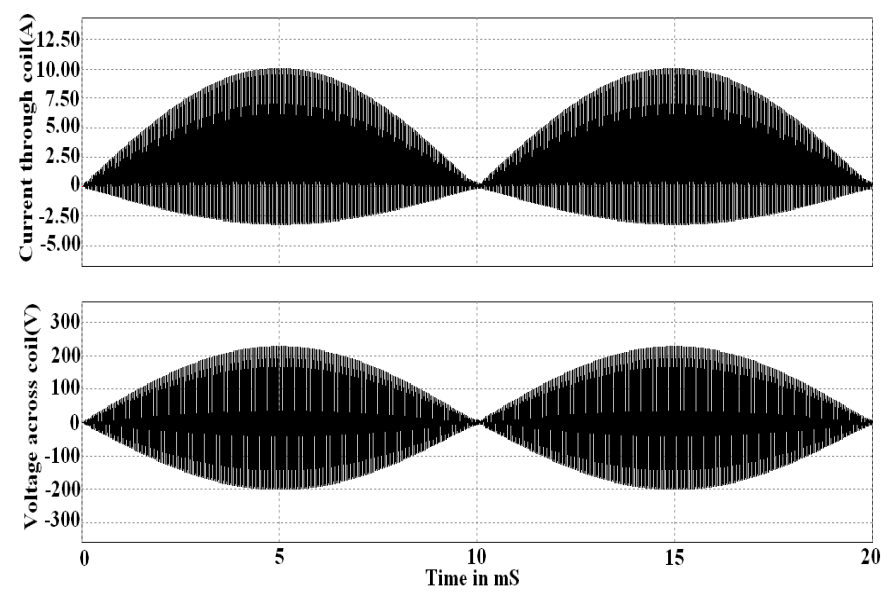

(a)

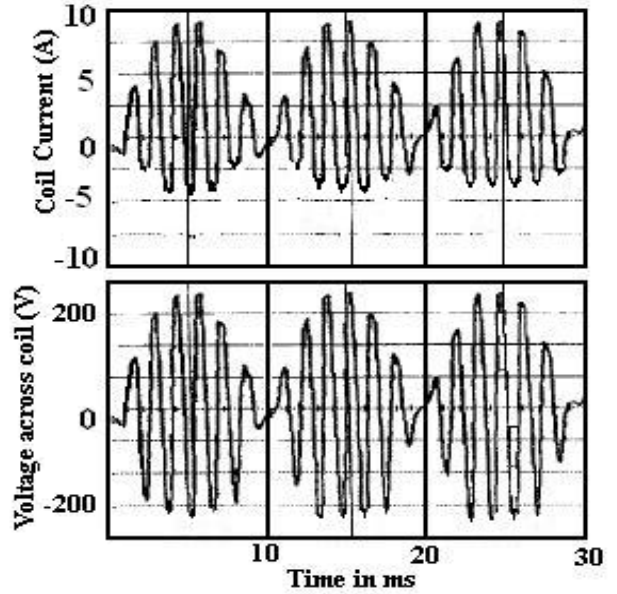

(b)

Figure 8: Coil current \& coil voltage using MOSFET by (a) PSPICE software and (b) real time experimental model

Using IGBT in the hybrid resonant inverter circuit, it is observed in Figure 6 (a) \& (b) that magnitude of current through the coil has almost equal in both positive and negative halves. Such a peak to peak symmetrical current produces more heat. Hence heating effect becomes very prominent for the same operating frequency range. Further, it is observed that the real voltage across heating coil and current through it, are almost identical to the PSPICE simulated result.

In Figure 7, the real voltage across heating coil and current through it, are almost indistinguishable to the PSPICE simulated result. But, current through the coil using GTO in the hybrid 
resonant inverter circuit, doesn't have equal positive and negative peaks. Hence, rms value of the current will be less. So heating effect will also be less compared to IGBT. Furthermore, GTO-based topology requires the arrangement of sending a negative gate pulse through the gate terminal of GTO in order to turn it off which enhances the circuit complexity.

Figure 8 depicts that using MOSFET in the hybrid resonant inverter circuit, the real voltage across heating coil and current through it, are almost same to the PSPICE simulated result. Here also, coil current doesn't have equal positive and negative peaks. Hence, rms value of the current will be less. So heating effect will also be less compared to IGBT.

\section{Photographs of Present DeVeloped System}
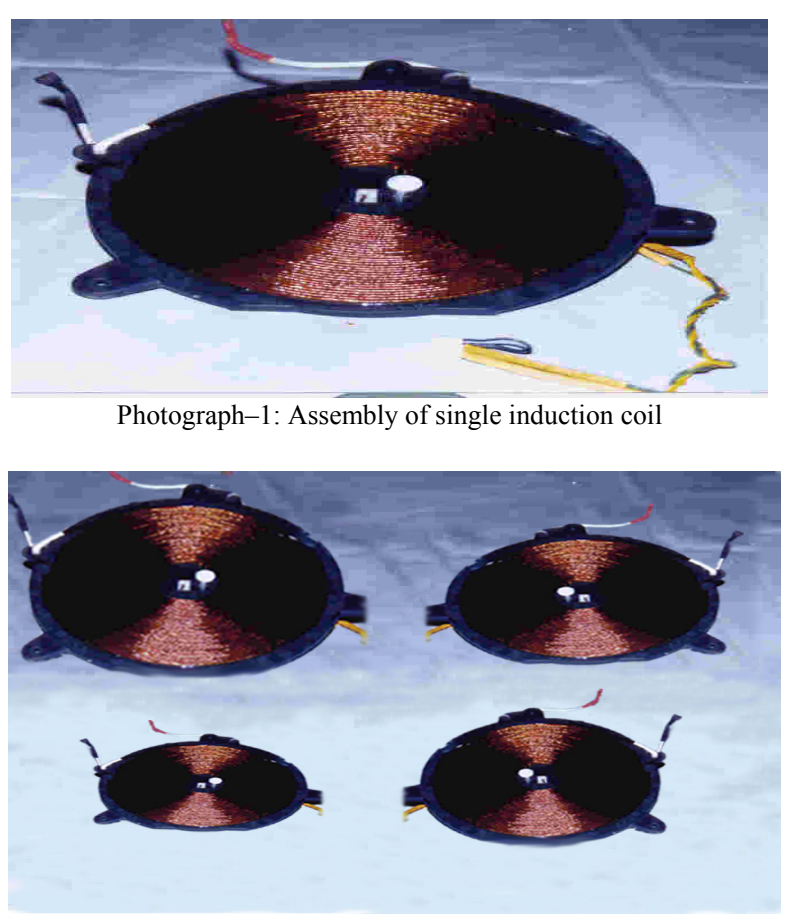

Photograph-2: Assembly of different diameters induction coils for multi-zones induction cooker

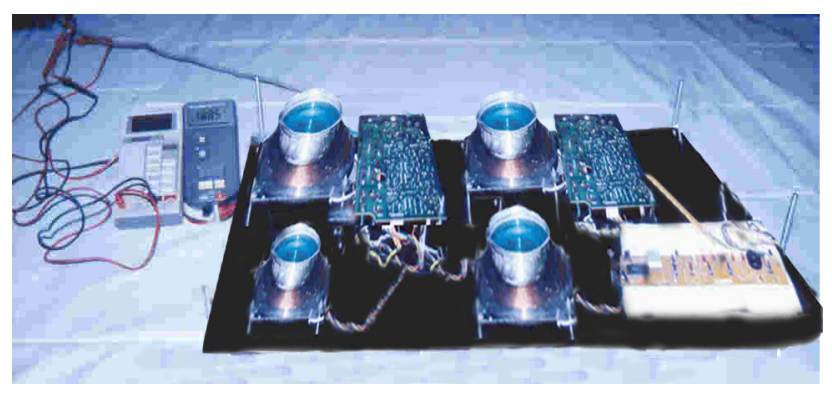

Photograph-3: Experimental setup of 4 zones induction cooker

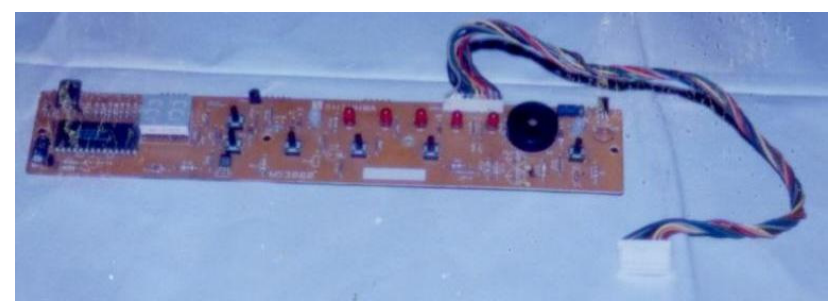

Photograph-4: Timer control PCB of 4 zones induction cooker

\section{CONCLUSION}

After having compared the wave-forms of PSPICE simulation and real time experiment, it is quite obvious that the selection of IGBT as a power semiconductor switch in high frequency hybrid resonant inverter is advantageous for induction heating purposes for frequency below $50 \mathrm{kHz}$ and highly acceptable. IGBT offers highest rms value of coil current among all the probable configurations using different power semiconductor switches. For a frequency range of above $50 \mathrm{kHz}$, MOSFET will be a better option due its low switching \& conduction losses.

\section{ACKNOWLEDGMENT}

Authors are thankful to the UNIVERSITY GRANTS COMMISSION, Bahadurshah Zafar Marg, New Delhi, India for granting financial support under Major Research Project entitled "Simulation of high-frequency mirror inverter for energy efficient induction heated cooking oven using PSPICE" w.e.f. 01 / 04 / 2008 to 31 / 03 / 2011. They are also grateful to the Under Secretary and Joint Secretary of UGC, India for their active co-operation.

\section{REFERENCES}

[1] P. K. Sadhu, N. Jana, R. Chakrabarti, and D. K. Mittra "A Unique Induction Heated Cooking Appliances Range Using Hybrid Resonant Converter" - Int. J. of Circuits, Systems and Computers, World Scientific, Volume 14, Number 3, June 2005, pp. 619-630.

[2] P. K. Sadhu, N. Pal, R. N. Chakrabarti and T.K Chatterjee, "Performance analysis of HF mirror inverter for energy efficient induction cooker appliance range", Int.Conf.on Modelling and simulation MS'07, University of Calcutta, December 2007, p. 444-448.

[3] P. K. Sadhu, N. Pal, A. Bandyopadhyay, and D. Sinha, "Review of Induction Cooking - a Health Hazards Free Tool to Improve Energy Efficiency as Compared to Microwave Oven", IEEE Proceeding of The $2^{\text {nd }}$ International Conference on Computer and Automation Engineering (ICCAE 2010) February 2010, Volume 5, p. 650-654.

[4] P. K. Sadhu, N. Pal, D. Sinha, and A. Bandyopadhyay, "Energy Efficient Induction Heated Cooking - Range using MCT baesd Hybrid Resonant Converter", IEEE Proceeding of The $2^{\text {nd }}$ International Conference on Computer and Automation Engineering (ICCAE 2010) Volume 5, February 2010, p. 637-641.

[5] P. K. Sadhu, S. K. Mukherjee, R. N. Chakrabarti, S. P. Chowdhury, and B. M. Karan, "Microprocessor-based energy efficient sterilization for surgical instrument using a new generation inverter topology," J. Energy, Heat \& Mass Transfer, Vol 23, No 1, March 2001, pp. 39-53.

[6] P. K. Sadhu, R. N. Chakrabarti, and S. P. Chowdhury, "An improved inverter circuit arrangement," Patent No. 69/Cal/2001, Patent Office Government of India.

[7] P. K. Sadhu, R. N. Chakrabarti, and S. P. Chowdhury, "A new generation fluid heating in non-metallic pipe-line using BJT and IGBT, ' J. Institution of Engineers (I), Vol 82, March 2002., pp. 273-280.

[8] P. K. Sadhu, R. N. Chakrabarti, and S. P. Chowdhury, "A heating apparatus using high frequency induction heating," Indian Patent No. 216361 (68/Cal/2001), Patent Office- Government of India.

[9] P. K. Sadhu, S. K. Mukherjee, R. N. Chakrabarti, S. P. Chowdhury, and B M. Karan, "A new generation microprocessor based radio-frequency operated induction heating for sterilization and boiler plant," J. IEEMA, Vol XXII, No 2, February 2002, pp. $36-48$.

[10] H. W.Koertzen, J.D.Van Wyk and J.A.Ferreira, 'Design of the half bridge series resonant converter for induction cooking," IEEE Power Electronics Specialists Conf. (PESC) Rec., 1995, pp. 729-735.

[11] F. P. Dawson, Praveen Jain, "Systems for induction heating \& melting applications, a comparison of load commutated inverter," IEEE, 1990.

[12] S. Llorente, F. Monterde, J.M.Burdio and J. Acero, "A comparative study of resonant inverter topologies used in induction cooker," IEEE Applied Power Electronics Conf. (APEC) Rec., 2002, pp. 1168-1174.

[13] P. K. Sadhu, S. K. Mukherjee, R. N. Chakrabarti, S. P. Chowdhury, and B. M. Karan,. "A new generation microprocessor based series resonant inverter for induction heating appliances," J. Industrial Engineering, Vol XXX, No. 9, September 2001, pp. $10-15$. 
[14] P. K. Sadhu, S. K. Mukherjee, R. N. Chakrabarti, S. P. Chowdhury, and B. M. Karan, "High efficient contamination free clean heat production," Indian Journal of Engineering \& Materials Sciences, National Institute of Science Communication, New Delhi, Vol-9, June 2002, pp. 172-176.

[15] J. P. Landis, "A static power supply for induction heating," IEEE-Trans, IECI, Vol.17 No. 4, September 1970, pp. 313-320.

[16] I. Gottlieb, Solid-state high-frequency power, Prentice-Hall 1989.

[17] M. Nakaoka, "A Phase-difference angle control- mode PWM high-frequency resonant inverters using static induction-transistors and thyristors," Proc. IEEE-PESC 87, June1987, p. 674-681.

[18] P. K. Sadhu, N. Pal, R. Chakrabarti, and D. K. Mittra, "A dynamic model for the simulation of induction cooktop," J. Industrial Engineering, Vol XXXV, No 6, June 2006, pp. 37-41.

[19] N. Pal, P. K. Sadhu, and R. N. Chakrabarti, "A Comparative Study of HF Mirror Inverter for Induction Cooker through Real-time and PSPICE Simulation,” J. Institution of Engineers (I), Vol 86, March 2006, pp. 268-274.

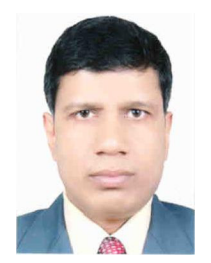

Nitai Pal received his B.Tech. and M.Tech. degrees in Electrical Engineering from University of Calcutta, West Bengal, India. He received his Ph.D. (Engineering) from Jadavpur University, West Bengal, India. He has total experience of twelve years in teaching. He is currently working as an Assistant Professor in the Department of Electrical Engineering, Indian School of Mines, Dhanbad, Jharkhand, India. He has several publications in Journals, International \& National conferences. He is the co-investigator of Govt funded project. A few students are pursuing doctoral study under him. Power electronics application, application of high frequency converters, energy efficient devices, energy efficient drives, lighting and communication systems for underground coal mines etc.

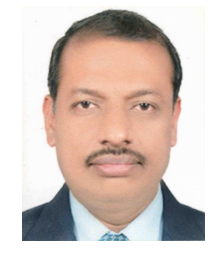

Pradip Kumar Sadhu received his Bachelor, Post-Graduate and Ph.D.(Engineering) degrees in 1997, 1999 and 2002 respectively in Electrical Engg. from Jadavpur University, West Bengal, India. Currently, he is working as a Professor in Electrical Engineering Department of Indian School of Mines, Dhanbad, India. He has total experience of 18 years in teaching and industry. He has four Patents. He has several journal and conference publications in national and international level. He is principal investigator of few Govt. funded projects. He has guided a large no. of doctoral candidates and M.Tech students. His current areas of interest are power electronics applications, application of high frequency converter, energy efficient devices, energy efficient drives, computer aided power system analysis, condition monitoring, lighting and communication systems for underground coal mines.

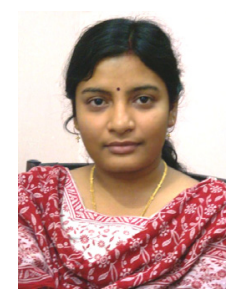

Dola Sinha completed B.E. and M. Tech. Degrees in Electrical Engineering from Burdwan University and National Institute of Technology, Durgapur - 713209, West Bengal, India in 2004 and 2006 respectively. She has worked as a faculty in the Department of Electrical Engineering, Dr. B. C. Roy Engineering College, Durgapur, India. She is presently pursuing Ph.D. Programme at the Department of Electrical Engineering, Indian School of Mines, Dhanbad - 826004, India. Her research interests include induction heating, power electronics and power systems.

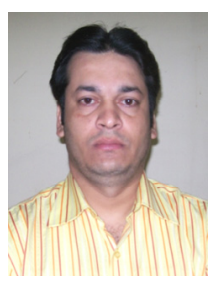

Atanu Bandyopadhyay completed B.E. from Nagpur University, India. He received his M.E. degree from Bengal Engineering and Science University, Shibpur, West Bengal, India. He has total experience of nine years in teaching and industry. He is currently working as an Assistant Professor in the Department of Electrical Engineering, Asansol Engineering College, Asansol-713305, West Bengal, India $\mathrm{He}$ is presently pursuing Ph.D. Programme under external registration at the Department of Electrical Engineering, Indian School of Mines, Dhanbad 826004, India. His research interests include induction heating and high frequency switching in power electronics. 